\title{
LA CRISIS DEL POSITIVISMO (VOSSLER, BAJTÍN, ORTEGA)
}

\section{Francisco Abad}

Universidad Nacional de Educación a Distancia

A Darío Villanueva: le agradezco su interés tan fraternal

\section{INTRODUCCIÓN}

La reciente traducción castellana - a partir de los originales rusosde las obras de V. N. Voloshinov El marxismo y la filosofía del lenguaje, y de P. N. Medvedev El método formal en los estudios literarios, no debe quedar desapercibida; en realidad estos escritos deben ser atribuidos (en un grado mayor o menor) a Mijaíl Bajtín. Nunca sabremos ciertamente en qué medida ambos libros son obra de Bajtín o de sus colaboradores, pero tampoco parece racional adscribirlos sólo a nombre del primero: sus discípulos debieron tener parte importante en ellos; de hecho en la traducción castellana El marxismo... aparece a nombre de Voloshinov, y El método formal... está firmado conjuntamente por Bajtín y por Medvedev. 
La presente versión española de estos escritos nos da pie para sugerir algo que creemos relevante: el complejo de pensamiento filosófico y lingüístico que acompañó a la teoría literaria en las décadas primeras de este siglo. Parece haberse perdido la conexión entre los estudiosos de cuestiones lingüísticas y los que se ocupan de problemas literarios, y de esta forma pasan desapercibidos hechos de relieve: alguna vez hemos llamado ya la atención sobre el dato - que creemos no había advertido la crítica - , de que la idea bajtiniana de la novela en cuanto género del plurilingüismo, resulta la versión en los estudios literarios de la idea contemporánea suya de la necesidad de una dialectología atenta a la diversificación interna de las comunidades idiomáticas.

\section{KARL VOSSLER}

Según decimos vamos a sugerir algunos de los hechos que constituyen un marco de conjunto unitario en el que se dieron la ciencia literaria y el pensamiento en general en las primeras décadas del siglo XX.

Punto de referencia necesario fue el pequeño libro de Karl Vossler de 1904 Positivismo e idealismo en la lingüística, en el que su autor caracteriza a los positivistas en cuanto empeñados en el conocimiento del hecho, del material, y a los «idealistas» por su búsqueda de la «comprensión y explicación causal»; nos encontramos así con que «se pide: ¿qué es? y ¿qué ocurre?. Esto es la ciencia rigurosa, objetiva», según el positivismo, pero «sáquese de nuestra razón el principio de causalidad y morirá», proclama Vossler (1929: 12-13).

«Idealismo» significa por tanto en la concepción de Vossler búsqueda de la explicación causal de los fenómenos filológicos; tal causa reside en el espíritu del hombre, en su capacidad racional y emocional: «la tarea que corresponde a la lingüística es hacer ver el espíritu como la única causa eficiente de todas las formas del lenguaje» (Vossler, 1929: 69). En particular el análisis literario consistirá en comparar la obra de arte con ella misma, en seguir las intuiciones del poeta y mostrar dónde y cómo ese poeta está en conflicto con su intuición y es infiel a su musa (Vossler, 1929: 49).

En el otro libro inmediatamente posterior, El lenguaje como creación y evolución(1905), el maestro entonces en Heidelberg se mueve en la traza de Rickert - aunque no lo advierta expresamente- al 
señalar cómo el historiador investiga «cuanto hay de particular y específico», o sea, cada obra literaria en tanto valor en sí, y advierte complementariamente que «la crítica estética del lenguaje como creación» pertenece lo mismo a la ciencia lingüística que a la Historia literaria (Vossler, 1929: 116 y 193).

Positivismo e idealismo... será conocido y tenido en cuenta por Bajtín, lo mismo que la Filosofía del lenguaje. En estos ensayos de los años diez de nuestra centuria opera Vossler con el concepto de «gusto idiomático de época», y proclama cómo la Historia lingüística debe explicar el cambio idiomático lo mismo en tanto «obra de todos los factores... que pueden comprobarse en la vida de un pueblo» que «como resultado del sentimiento o gusto idiomático»(Vossler, 1953: 38 y 45). Aunque quizá nadie lo ha subrayado hasta ahora, la verdad es que esta idea de los gustos idiomáticos de época fue la que hizo suya también Menéndez Pidal al trazar los capítulos de su inacabada Historia breve de la lengua española, al referirse a los procesos fonéticos de larga duración y a la coexistencia de tendencias y procesos en los estados de lengua; don Ramón heredó a Vossler cuando éste proclamaba - según hemos visto- que la Historia lingüística es «historia del gusto o sentimiento idiomático» (1963: 49).

Léase - como decimos-Orígenes..., o por ejemplo lo que hoy es el volumen pidalino La lengua castellana en el siglo XVII (1991), y se advertirá la herencia vossleriana en Menéndez Pidal, su misma búsqueda de los gustos idiomáticos de época igual en las centurias primeras de la lengua que en el idioma del Barroco español.

\section{EL FORMALISMO RUSO}

Asimismo en los años diez de nuestro siglo escribió Charles Bally su trabajo El lenguaje y la vida, y en el mismo parece sugerir que la lengua literaria ha salido del lenguaje espontáneo «gracias a la transformación del medio en fin» (Bally, 1967: 39); de manera convergente - por tanto- con el formalismo ruso, nuestro autor advierte que la lengua literaria constituye un «fin», y se caracteriza así por su vocabulario, por clisés, por construcciones sintácticas determinadas, etc. A su vez Vinogradov (por ejemplo) operaba con esta idea implícita de la finalidad en sí mismo del discurso poético, y por ello definía cada obra literaria en tanto un sistema propio de correlaciones estilísticas (Todorov, 1970: 81). 
En efecto Vinogradov postulaba un «método de estudios estilísticos funcional e inmanente», y decía que resultaba análogo a lo que en lingüística hacían Saussure, Meillet, y otros autores (Tovorov, 1970: 82). La inmanencia del decurso en sí tanto idiomático como literario quedaba resaltada lo mismo por los lingüistas que por los críticos en estos años diez y veinte del siglo; alguna convergencia hacia la misma idea manifestaba asimismo Bally. En realidad lo inmanente no reside sólo en el sistema, sino que está también en la tradición o «serie»; de esta manera Vinogradov podía proclamar por fin:

EI historiador de los estilos poéticos establece las relaciones de [las] obras con los estilos de la época contemporánea y del pasado, y observa las sombras cambiantes que ellas proyectan sobre los períodos siguientes provocando así la creación de nuevas formas lingüísticas (Todorov, 1970: 84).

Lo lingüístico y lo literario constituyen por tanto «series» o tradiciones, un conjunto diacrónico de inmanencias: así se veían las cosas por los estudiosos en las primeras décadas de nuestro siglo.

La idea de que lo filológico consiste en una finalidad interna viene en realidad de Kant; no creemos que se haya interpretado hasta ahora así, pero por nuestra parte lo entendemos de esta manera. Kant definió lo bello en tanto una finalidad sin fin, y este concepto de un sistema teleológico es el que vinieron a hacer suyo los formalistas rusos, y asimismo la lingüística estructural-funcional.

Las ideas de inmanencia, de tradición interior o inmanente, de sistema funcional, etc., que en parte están sugeridas por la de «finalidad sin fin» kantiana, presiden el desarrollo de la teorización en los estudios filológicos en el primer tercio de nuestro siglo que estamos considerando.

\section{ORTEGA}

Como es sabido en 1925 publicó Ortega y Gasset La deshumanización del arte, escrito concebido en tanto un intento «de filiar el arte nuevo»: estamos en efecto ante una poética del arte de vanguardia, poética penetrante y certera. Ortega ve así que «el objeto artístico sólo es artístico en la medida en que no es real», es decir, que subraya lo 
que el arte nuevo tiene de inmanente o intransitivo, de construcción que vale por sí misma y antes que nada por sí misma: importa menos por su referencia a la realidad (Ortega, 1966: 358).

Este arte consiste sobre todo en una construcción específica, y por ello sólo lo entenderán de verdad quienes posean una facultad y una educación estéticas: «sólo puede ser percibido - nota Ortega- por quien posea ese don peculiar de la sensibilidad artística», por lo que en buena manera resulta «un arte para artistas» (Ortega, 1966: 359).

Se trata - según decimos- de una construcción estética que no remite primaria e inmediatamente a la realidad, y que por ello tiende a «evitar las formas vivas», o sea, tiende a hacerse un constructo formal -intransitivo; ante ello proclama el pensador madrileño: «Lograr construir algo que no sea copia de lo «natural» y que, sin embargo, posea alguna sustantividad, implica el don más sublime» (Ortega, 1966: 360 y 366). El camino de este arte nuevo «se llama voluntad de estilo», es decir, construcción formal intransitiva e inmanente, valor estético por sí mismo aunque necesariamente acabe por remitir a la realidad - podemos añadir por nuestra cuenta; el arte nuevo «triunfa de todo, incluso de sí mismo, a la manera que en un sistema de espejos reflejándose indefinidamente los unos en los otros ninguna forma es la última» (Ortega, 1966: 368 y 383).

\section{ANTE EL POSITIVISMO Y EL IDEALISMO}

El libro de Bajtín o Medvedev es, como queda dicho, El método formal en los estudios literarios, de 1928, y en el mismo se reacciona por ejemplo - al modo de Vossler unos lustros antes- contra el mero positivismo, un positivismo «incapaz de realizar síntesis alguna»; sin embargo proclama Bajtín (o Medvedev) que ha surgido ya «un profundo deseo de unificar los problemas en una extensa síntesis... que incluiría el estudio concreto de la... pluralidad, especificidad y concreción material de los fenómenos ideológicos» (Bajtín, 1994: 43). Se trata pues de sustituir el positivismo de la mera comprobación empírica, por otro género de positivismo que aclare la especificidad real y la inserción real de los hechos del espíritu.

Bajtín habla de la «crisis simultánea» del idealismo y del positivismo, y postula el análisis específico del sentido de cada individualidad histórica: 
En los estudios estéticos actuales - proclama - se busca penetrar, mediante un sentido unitario, en el mundo de las cosas concretas y de los sucesos históricos concretos en su irrepetibilidad e individualidad... [Se trata] de dominar el mundo concreto de las cosas y de los acontecimientos que se manifiestan materialmente, superando sin embargo los fundamentos positivistas y sin que se pierda la unidad viviente y significativa de las cosas (Bajtín, 1994: 45).

Ante la que se estima crisis del positivismo y del idealismo, nos encontramos con el postulado del análisis del sentido unitario que posean los sucesos concretos de la historia estética.

De manera muy nítida nos dicen nuestros autores que la literatura refracta a su modo la existencia socioeconómica, es decir, que refleja en su contenido la totalidad del horizonte ideológico del que forma parte: «el medio ideológico es la única atmósfera en la que la vida, en cuanto objeto de representación literaria, puede llevarse a cabo» (Bajtín, 1994: 60). La vida aparece representada artísticamente en los discursos literarios, pero esa representación lleva ineluctablemente el sesgo anímico e ideológico del autor: Ortega - por ejemplo- hemos visto que escribió a favor del arte de vanguardia, como más o menos a la vez Blasco se manifestaba anticlericalmente o Américo Castro en contra de las instituciones de la España de Alfonso XIII; siglos antes Quevedo se manifestó en contra del ímpetu ascensional del estado llano, en una serie de pensamiento en la que a la vez antes había estado también el príncipe don Juan Manuel, etc.

Por supuesto - no obstante - la literatura es arte y no pensamiento estricto: no se trata de un puro discurso ideológico, sino de un texto que no puede dejar de hacer alusión a la realidad, pues en efecto todo autor vive y respira en un atmósfera ideológica, sea consciente de ella o no. «En la literatura no hay filosofía sino tan sólo un filosofar; no hay conocimiento sino cognición» (Bajtín, 1994: 64).

En fin puede recordarse que Bajtín o Medvedev valoran en los formalistas (rusos) que hayan sabido hacerse cargo de la especificidad de lo literario, pero disienten de ellos en que no han sabido concebir tal especificidad o singularidad de lo artístico de manera dialéctica, y por tanto «son incapaces de combinarla con la viva interacción en la unidad concreta de la vida histórico-social» (Bajtín, 1994: 86).

El otro libro de Voloshinov o Bajtín, el referido a El marxismo y la filosofía del lenguaje, era ya conocido entre nosotros por su versión francesa y por una retraducción hecha al castellano; personalmente lo reseñamos un par de veces en su día. 
Bajtín ahora, en 1929, recoge el sentido de las investigaciones de lo que llama «la escuela de Vossler» (por ejemplo vid. Voloshinov, 1992: 79-80), pero frente a ella postula un punto de vista histórico-sociológico concreto en el análisis del lenguaje; el autor de este texto mantiene así: «El lenguaje es un proceso continuo de generación llevado a cabo en la interacción discursiva social de los hablantes... Las leyes de la generación lingüística son sociológicas... La estructura del enunciado es puramente sociológica. El enunciado como tal surge entre los hablantes» (Voloshinov, 1992: 137).

\title{
OTRA VEZ VOSSLER Y ORTEGA
}

Vossler (1929: 92) había señalado en 1904 cómo «la gramática debe... resolverse en la Estilística»; casi medio siglo más tarde Ortega y Gasset se hace eco de la idea y manifiesta:

\begin{abstract}
La estilística no es... un vago añadido a la gramática, sino que es ni más ni menos toda una nueva lingüística incipiente, que se resuelve a tomar el lenguaje más cerca de su concreta realidad... La reciente estilística, hoy breve orla que escarola el severo perfil de la gramática y el léxico, está destinada a tragarse a éstos y a alzarse con el santo y la limosna de toda la lingüística (Ortega, 1969: 247).
\end{abstract}

El autor madrileño es muy consciente de que ser un buen escritor consiste en «erosionar» gramática y léxico (Ortega, 1969: 246). Ortega no es aquí positivista, sino que intenta falsar el positivismo en un sentido análogo al de Karl Vossler en parte: por la ampliación del material empírico considerado.

\section{CONCLUSIONES}

1. Karl Vossler entiende el «idealismo» en filología en tanto estudio de las causas espirituales de las manifestaciones lingüísticas y literarias.

2. Entre tales causas se encuentra la del «sentimiento o gusto idio- 
mático», gusto de acuerdo con el que analizó Menéndez Pidal —por ejemplo- las distintas épocas de la lengua española.

3. Ortega y Gasset por su parte pide con Vossler una falsación del estricto positivismo, en cuanto ha de ampliarse el objeto empírico considerado hasta comprender en él los hechos de estilo individual.

4. Bajtín y su escuela certifican la crisis a la vez del positivismo y del idealismo filológicos: crisis del positivismo porque el estudioso debe alcanzar el sentido de la concreción material de los fenómenos considerados.

5. Frente al idealismo Bajtín postula que los enunciados lingüísticos están en dependencia de la interacción discursiva social de los hablantes.

6. Se trata pues en todo caso - para el grupo de Bajtín- de analizar y establecer la unicidad concreta de la vida histórico-social.

7. Junto a las posturas investigadoras respectivas de Vossler y de Bajtín, los formalistas rusos enunciaron la suya de un propósito de análisis inmanente y funcional de las obras y de la serie literarias. En realidad la perspectiva interna y teleológica a la hora de estudiar el lenguaje y lo poético procede de Kant, de su «finalidad sin fin» como fundamento de la obra de arte.

8. Ortega y Gasset, en paralelo con el formalismo europeo, caracteriza el «arte nuevo» - el arte de los años veinte, según Antonio Espina (1965: 127) - por su primaria voluntad formalista de estilo.

9. De acuerdo con Bajtín la literatura no es pensamiento propiamente dicho, aunque se piensa en ella; cualquier representación literaria de la realidad posee un sesgo o tono ideológico.

10. Con carácter general, puede decirse que la historia de las ideas literarias del siglo $\mathrm{xX}$ necesita que se tengan en cuenta a la vez la historia de las ideas lingüísticas y la del pensamiento todo. 


\section{Referencias bibliográficas}

BAJTín, M. (P.N. Medvedev) (1994). El método formal en los estudios literarios. Madrid: Alianza.

BALLY, CH. (1967). El lenguaje y la vida. Buenos Aires: Losada.

ESPINA, A. (1965). El genio cómico. Santiago de Chile: Cruz del Sur.

ORTEGA Y GASSET, J. (1966). Obras Completas, III. Madrid: Revista de Occidente.

OrtegA y Gasset, J. (1969). Obras Completas, VIII. Madrid: Revista de Occidente.

Todorov, T. (ed.) (1970). Teoría de la literatura de los formalistas rusos. Buenos Aires: Signos.

Voloshinov, V.N. (1992). El marxismo y la filosofía del lenguaje. Madrid: Alianza.

VOSSlER. K. (1929). Positivismo e idealismo en la lingüística y El lenguaje como creación y evolución. Madrid: Poblet.

Vossler, K. (1963). Filosofía del lenguaje. Buenos Aires: Losada.

NOTA. Sobre la crisis del positivismo ha hecho su tesis doctoral José Portolés (1986). Medio siglo de filología española (1896-1952). Madrid: Cátedra. Junto a percepciones certeras el autor hace otras con las que coincidimos menos; en particular nuestra visión de los hechos es distinta por cuanto no compartimos el tono general un tanto negativo hacia los libros de la escuela pidalina, ni nos parece que quepa prescindir de la geografía lingüística como medio de falsación del positivismo, ni que quepa prescindir de un estudioso como Lapesa. 